\title{
DESIGN THINKING NA ELABORAÇÃO DE UMA PROPOSTA DE SINALIZAÇÃO DA BIBLIOTECA UNIVERSITÁRIA DA UFCA: RELATO DE PESQUISA
}

\author{
DESIGN THINKING ON THE CREATION OF A UFCA \\ ACADEMIC LIBRARY SIGNALING PROPOSAL: \\ RESEARCH REPORT
}

\author{
Isaac Brito Roquea \\ David Vernon Vieirab
}

\begin{abstract}
RESUMO
Introdução: Diante das mudanças ocorridas nos últimos anos no ambiente das bibliotecas universitárias a gestão deste espaço se depara com um novo tipo de usuário já acostumado com a tecnologia da informação que criou novos anseios. A sinalização deve então ser pensada para esse tipo de usuário bem como ampliar também para a questão da acessibilidade assim, é importante rever os serviços e produtos oferecidos pela biblioteca dentro deste enfoque. Objetivo: Apresentar um relato de pesquisa sobre a concepção de soluções de sinalização utilizando ferramentas do Design Thinking com o engajamento de usuários da Biblioteca Central da Universidade Federal do Cariri (UFCA). Metodologia: De natureza qualitativa o estudo compreendeu a utilização de um grupo focal onde foram entrevistados dez usuários da Biblioteca Universitária da UFCA. De natureza prática e com objetivos exploratórios, sua abordagem foi no formato de pesquisa-ação, visando promover a cooperação dos usuários da biblioteca do Campus de Juazeiro do Norte na concepção de soluções de sinalização do ambiente. Resultados: Percebeu-se um engajamento colaborativo entre os participantes, envolvendo-os de maneira protagonista e entusiasmada para os desafios de identificar os problemas e propor soluções para a biblioteca. A utilização das etapas e das ferramentas do Design Thinking, ainda que registradas de maneira linear, procurou se adequar ao processo de maneira satisfatória segundo o relato do próprio grupo focal. Conclusões: A colaboração entre as disciplinas de Design e a Ciência da Informação representa uma oportunidade para aproximar a prática do Design Thinking com intuito de otimizar sistemas de sinalização de bibliotecas, embora tenha se demonstrado que os métodos abordados são capazes de alcançar soluções ainda mais amplas. Sobretudo, o principal destaque a se considerar é a inserção dos usuários como parte fundamental no planejamento e estratégias do campo da ciência da informação.

\footnotetext{
a Docente do Curso de Design da Universidade Federal do Cariri. Mestre em Biblioteconomia, pela Universidade Federal do Cariri (UFCA). E-mail: isaac.brito@ufca.edu.br

b Professor do Curso de Biblioteconomia e do Programa de Pós-Graduação em Biblioteconomia, da Universidade Federal do Cariri (UFCA). Doutor em Ciência da Informação, pela Universidade de Brasília (UnB).E-mail: david.vieira@ufca.edu.br
} 
Descritores: Design Thinking. Biblioteca Universitária. Sinalização. Ferramentas.

\section{INTRODUÇÃO}

Há alguns anos as bibliotecas vem tentando mudar sua perspectiva que anteriormente era centrada no acervo para um ambiente que sirva como laboratório de experimentação que permita criar novos conteúdos e desenvolver a aprendizagem dos seus usuários.

John (2016) apresenta em relatório publicado pelo British Council essa nova perspectiva centrada no engajamento com os usuários por meio de estudo em bibliotecas públicas na Holanda, Finlândia, Dinamarca, EUA e Canadá. Para isso, o estudo foi dividido em três partes: a) Inspirando as bibliotecas (Inspiring Libraries) - ressaltando as principais funções observadas e descrevendo como elas encorajam os seus usuários; b) Projetando as bibliotecas (Designing Libraries) - foca nas características de design contemporâneo que ressaltam as bibliotecas em relação ao urbanismo, arquitetura e design de interiores; c) Usuários em evolução (Evolving Users) - explora os desafios e oportunidades de design para os colaboradores e usuários de bibliotecas considerando como exemplo a Biblioteca Pública de Seattle nos EUA, de modo a criar uma melhor experiência com o usuário.

Melo e Abelheira (2015) destacam que as origens do termo "design" vêm do latim designare, contudo o termo em inglês está comumente traduzido para "projeto", porém, muitas vezes está associado a representação ou ilustração. Estes autores ressaltam ainda que o design está no ponto de contato entre um produto/marca/serviço com o usuário. Daí surgirem termos como "design gráfico" que envolve a comunicação e a arte; o "design de produto" que com a revolução industrial assumiu uma condição importante pois com a produção em massa era necessário realizar uma análise prévia antes de colocar o produto à venda; e o "design de interfaces" em que na era da tecnologia da informação com o desenvolvimento de dispositivos de entrada e saída de informações exige cada vez mais adaptações que permitam uma melhor interação.

Vale ressaltar que, se formos transpor esses termos ou conceitos citados 
anteriormente para o ambiente das bibliotecas eles são perfeitamente incorporados visto que para realizar a mediação da informação requer uma boa comunicação, uma boa apresentação e quando necessário uma interação para transmitir a informação que o usuário necessita.

O presente artigo apresenta um relato de pesquisa sobre a concepção de soluções de sinalização utilizando ferramentas do Design Thinking com o engajamento de usuários da Biblioteca Central da Universidade Federal do Cariri (UFCA).

\section{A ABORDAGEM DO DESIGN THINKING}

O termo Design Thinking segundo Pinheiro (2011) foi mencionado pela primeira vez em 1992 em artigo escrito por Richard Buchanan, professor da Universidade de Carnegie Mellon nos EUA, intitulado "Wicked Problems in Design Thinking".

Pinheiro (2011, p. 48) ressalta que em seu conteúdo o artigo de Buchanan destacava que a evolução do Design já não permite ficar restrito a uma mera disciplina, e sim que eleve o seu potencial de abordagem considerando que:

a) O Design ganha força na comunicação visual, estendendo seu foco da parte gráfica para a fotografia e a televisão; b) o Design de produtos ganha também um olhar fundamental voltado para a função, indo buscar na engenharia e ciências sociais razões para as coisas existirem; c) o Design aplicado a Serviços, traz para o desenho de processos o seu pensamento holístico e o foco nas pessoas; d) O Design como abordagem na construção de melhores ambientes para as pessoas viverem e trabalharem.

Segundo Brown (2008) existem três fases para desenvolver a abordagem do Design Thinking (DT): 1) a inspiração - leva-se em conta o que tem de expectativa do produto ou serviço (brainstorming) que é o foco do problema em questão e, neste caso requer uma observação holística (tecnologia, reunião, observação) que ajude a contribuir com o objetivo final; 2) a ideação - onde levase em conta o que foi analisado na fase anterior para permitir a criação de cenários de modo que originem um marco de referência que permita a integração das ideias que surgiram e, portanto possa gerar um protótipo; 3) a implementação - com o desenvolvimento do produto, serviço ou processo e o 
posterior teste pelo usuário final junto com a equipe interna do projeto, surgem as ações de marketing e comunicação que permitem efetivar a inovação esperada.

Então como seria adaptar o Design Thinking para as bibliotecas? De acordo com Burguillos (2016, p. 109) o Design Thinking para bibliotecas é:

[...] uma metodologia de solução de problemas com uma abordagem criativa, prática, intencional e repetitiva, que visa estimular soluções inovadoras e responder às reais necessidades dos usuários, melhorando o resultado obtido e, consequentemente, sua experiência em relação aos usuários.

Neste sentido, com um olhar voltado para as bibliotecas percebe-se que os produtos e serviços sendo analisados com as ferramentas do Design Thinking podem assumir uma condição favorável para que os usuários aproveitem melhor esses recursos informacionais.

A organização IDEO desenvolveu um kit de ferramentas conhecida por Design Thinking for Libraries (tradução Design Thinking para Bibliotecas) para que fosse utilizada em projeto financiado pela Fundação Bill e Melinda Gates junto com diversas bibliotecas públicas de diversos países inscritas neste projeto. De acordo com Burguillos (2016) deste kit de ferramentas constam três documentos. O primeiro (Toolkit guide for patron-centered design - Design Thinking para Bibliotecas um toolkit para design centrado no usuário) corresponde ao documento principal onde constam os significados e conceitos com exemplos e estudos de caso sobre a metodologia. O segundo (Activities workbook - Caderno de Atividades) fornece uma coleção de atividades para ajudar os bibliotecários a desenvolver um projeto usando a metodologia e planilhas que ajudam a prototipar e obter informação necessária dos usuários sobre produtos e serviços oferecidos pela biblioteca. O terceiro documento (Design thinking in a day: an at-a-glance guide for advancing your library - Design Thinking em um dia: um guia rápido para fazer avançar sua biblioteca) nada mais é que um resumo do primeiro para ajudar a dar início ao projeto usando a metodologia.

Vale ressaltar, que aqui no Brasil a Federação Brasileira de Associações de Bibliotecários, Cientistas da Informação e Instituições (FEBAB) traduziu os dois primeiros documentos para promover essa metodologia entre as bibliotecas 
brasileiras, tendo inclusive promovido sessões da metodologia no Congresso Brasileiro de Biblioteconomia e Documentação (CBBD) desde 2017.

De acordo com Macedo e Santos (2016) as bibliotecas podem inovar com o Design Thinking em vários aspectos: a) atividades e eventos - os bibliotecários podem com o DT ter um melhor entendimento das pessoas e a dinâmica do entorno da biblioteca; b) serviços - é possível remodelar os serviços articulando tecnologias disponíveis com as necessidades dos usuários; c) espaços - é preciso criar novas experiências para os usuários nos espaços da biblioteca fazendo isso por meio da mudança nas interações e nos fluxos que podem ir além do espaço físico; d) sistemas - é preciso realizar a integração dos sistemas independentes existentes no ambiente da biblioteca seja com o público ou com os próprios colaboradores. Em suma, a amplitude que o DT traz para essa nova perspectiva que envolve a biblioteca centrada no usuário favorece em muito ao seu emprego neste espaço.

Aqui no Brasil, além do capítulo de ebook citado no parágrafo anterior já é possível encontrar algumas pesquisas em português envolvendo o uso do Design Thinking (DT) em Bibliotecas. Bernal-Ramirez e Zaninelli (2017) apresentam um levantamento bibliográfico sobre o assunto tendo a abordagem do DT como suporte no processo de inovação nos serviços informacionais em bibliotecas universitárias. As autoras destacam três casos de uso do DT na Biblioteca Pública de Chicago nos EUA, na Biblioteca da Universidade do Estado de Santa Catarina (UDESC) e no Sistema de Bibliotecas de Bogotá na Colômbia e concluem que a etapa de prototipagem é muito importante visto que é nela onde os desejos e necessidades dos usuários são contemplados. Juliani, Cavaglieri e Machado (2015) concentraram o seu estudo na Biblioteca da UDESC onde procuraram utilizar as técnicas do DT como ferramenta para geração de ideias inovadoras.

\section{METODOLOGIA}

A presente pesquisa caracteriza-se como estudo de caso, pois foi estruturada e desenvolvida para solucionar problemas de sinalização na Biblioteca 
da Universidade Federal do Cariri (UFCA) - Campus Juazeiro do Norte.

A abordagem do problema destacado se configura como qualitativa e de natureza prática, com objetivo exploratório, pois se propõe a realizar um estudo de caso de interesse prático para a solução de problemas reais. A aplicação metodológica, por sua vez, possui procedimento técnico no formato de pesquisaação, pois age com a participação direta dos participantes e dos pesquisados na resolução de problemas coletivos, promovendo a cooperação dos membros envolvidos na situação investigada (GIL, 2012).

As etapas metodológicas foram baseadas do toolkit Design Thinking for libraries, elaborada pela empresa IDEO. As ferramentas utilizadas nestas etapas foram o diário pessoal, registro fotográfico, mapa de jornada, mapeamento dois por dois, e mapa de relacionamento, dos quais serão explicados no decorrer da leitura.

O processo de coleta de dados está integrada etapa de inspiração, na qual foram utilizados dois momentos de análise, um pelo mediador e outro pelo grupo focal (composto por 3 alunos e 3 servidores). À princípio, o mediador entrevistou dez usuários da biblioteca para coletar informações complementares ao grupo focal. No segundo momento, este grupo aplicou os métodos do Design Thinking para averiguar os problemas de sinalização. A pesquisa ocorreu no em março de 2018 nas dependências da Biblioteca da UFCA.

\section{RESULTADOS ALCANÇADOS}

Localizada em Juazeiro do Norte (CE), a Biblioteca Central da UFCA é uma entre as cinco bibliotecas espalhadas pelos demais campi. Segundo o projeto arquitetônico da Biblioteca, o espaço está configurado com o seguinte layout: sala de leitura, hall de recepção, recepção, empréstimo/devolução, guarda volumes, bibliotecária, acervo, hall de leitura, leitura em grupo 01, leitura em grupo 02 , multimídia, leitura individual, sala de processamento técnico e coleções.

Para identificar e sanar os problemas de sinalização nesta biblioteca, foram necessárias algumas adaptações da metodologia do Design Thinking em razão de algumas características da pesquisa. Assim, nem todas as ferramentas, assim como algumas das fases sugeridas pelo toolkit, foram utilizadas. Portanto, 
neste estudo, o grupo focal executou as etapas de inspiração e ideação. Por outro lado, a criação das propostas gráficas da sinalização na etapa de iteração foi executada pelo autor da pesquisa, considerando os resultados das etapas anteriores do design thinking, a normatização da ABNT 9050 e o Manual de Sinalização' ${ }^{1}$ da UFCA desenvolvido pela empresa VERDI.

\subsection{INSPIRAÇÃo}

A fase de inspiração é executada sobre as ações de escutar, observar e ater-se ao inesperado. É necessário destacar que o processo de inspiração não acontece ao acaso, por meio de insights ${ }^{2}$, mas trata-se de uma exploração ativa com direito a preparação, que servirá como base para as etapas subsequentes. Esta etapa foi dividida em quatro passos, como demonstra o quadro 1 :

\section{Quadro 1 - Etapas do processo de inspiração}

\begin{tabular}{|l|l|l|}
\hline Ação & Atividade & Objetivos \\
\hline Passo 1 & Definição do desafio de design & $\begin{array}{l}\text { - Identificação do público-usuário } \\
\text { - Identificação do problema } \\
\text { - Analisar as restrições }\end{array}$ \\
\hline Passo 2 & Exploração do método de pesquisa & $\begin{array}{l}\text { - Observação dos espaços } \\
\text { - Experiência Imersiva }\end{array}$ \\
\hline Passo 3 & Planejamento da pesquisa & $\begin{array}{l}\text { - Realizar o percurso do Mapa da } \\
\text { Jornada } \\
\text { - Fazer anotações no diário pessoal } \\
\text { - Realizar registro fotográfico }\end{array}$ \\
\hline Passo 4 & Documentação durante a pesquisa & - Organização e registro \\
\hline
\end{tabular}

Fonte: Elaborado pelos autores (2019).

O primeiro passo consistiu na "definição do desafio do design" que propunha compreender os comportamentos, sensações e emoções do público, identificar os problemas de sinalização da biblioteca para que em seguida

\footnotetext{
1 Disponível em:https://www.ufca.edu.br/instituicao/administrativo/estruturaorganizacional/orgaos-suplementares/dcom/documentos/. Acesso em: 10 mai. 2018.

2 Insights são expressões concisas do que você aprendeu com as atividades de pesquisa. Combinam observação com deduções para criar um novo significado. Eles refletem uma compreensão do assunto em questão e são inesperados, não óbvios e interessantes. Insights permitem que você veja o mundo de uma nova maneira e são os catalisadores de novas ideias (IDEO, 2017, p. 55).
} 
possam ser analisadas as restrições que impedem ou dificultam suas soluções. Portanto, neste trabalho o processo foi dividido em duas atividades, uma para 0 mediador e outra para o grupo focal.

O mediador buscou reconhecer o perfil do público-usuário realizando entrevistas, com intuito de compreender a percepção que eles possuem em relação à sinalização da biblioteca e como esta pode beneficiar suas necessidades. A segunda atividade foi executada pelo grupo focal que pretendeu identificar os problemas de sinalização, considerando uma análise imersiva através das condições do espaço, do tempo e dos recursos disponíveis para execução e/ou implementação das propostas.

O passo dois tratou da "exploração do método de pesquisa" que visava preparar os integrantes do grupo focal aos próximos desafios, realizado 0 planejamento e a seleção dos métodos a serem aplicados nas fases seguintes. Definiu-se, portanto, o uso da "observação" e da "experiência imersiva" como principais métodos a serem explorados, de modo que para esta observação foram utilizadas as seguintes ferramentas de DT:

- Diário pessoal: os integrantes fazem anotações pertinentes para serem explorados em discussões posteriores. O material foi disponibilizado pelo mediador.

- Registro fotográfico: o mediador, com apoio de um assistente, ficou responsável pelo registro fotográfico das atividades.

- Mapa de Jornada: um mapa fornece aos integrantes alguns percursos com intuito de identificarem os problemas de sinalização dos ambientes internos e externos da biblioteca.

A "experiência imersiva" tratou de uma ação que visava promover aos integrantes do grupo focal a vivencia dos comportamentos dos usuários, possibilitando também que os usuários compreendam os atributos e a ótica dos funcionários - princípio da empatia. Com isso, a IDEO (2017) acredita que o método é capaz de ampliar as ideias dos participantes, para que se sensibilizem e percebam as características de ambos os papéis.

Para o terceiro passo foram executados os métodos definidos na etapa anterior. Desse modo, a primeira atividade consta na observação dos espaços 
que envolvem toda a dinâmica do percurso da biblioteca. Portanto, os participantes foram submetidos a realizar um determinado caminho com apoio do diário pessoal e o mapa da jornada, ao passo que o mediador fez os registros fotográficos necessários. Inicialmente a dinâmica ocorreu na entrada do campus, seguindo pelo pátio até chegar nas mediações do prédio onde está localizada a biblioteca. O segundo percurso já havia sido delimitado no mapa da jornada, pois tratava do espaço interno da biblioteca.

Por fim, o quarto passo consistiu na documentação e registro de toda a pesquisa por parte do mediador, que ficou responsável em disponibilizar organizadamente todas as informações para a etapa de ideação. O esquema a seguir (figura 1) possibilita uma melhor visualização dos processos descritos na fase de inspiração.

Figura 1 - Passos da etapa de inspiração

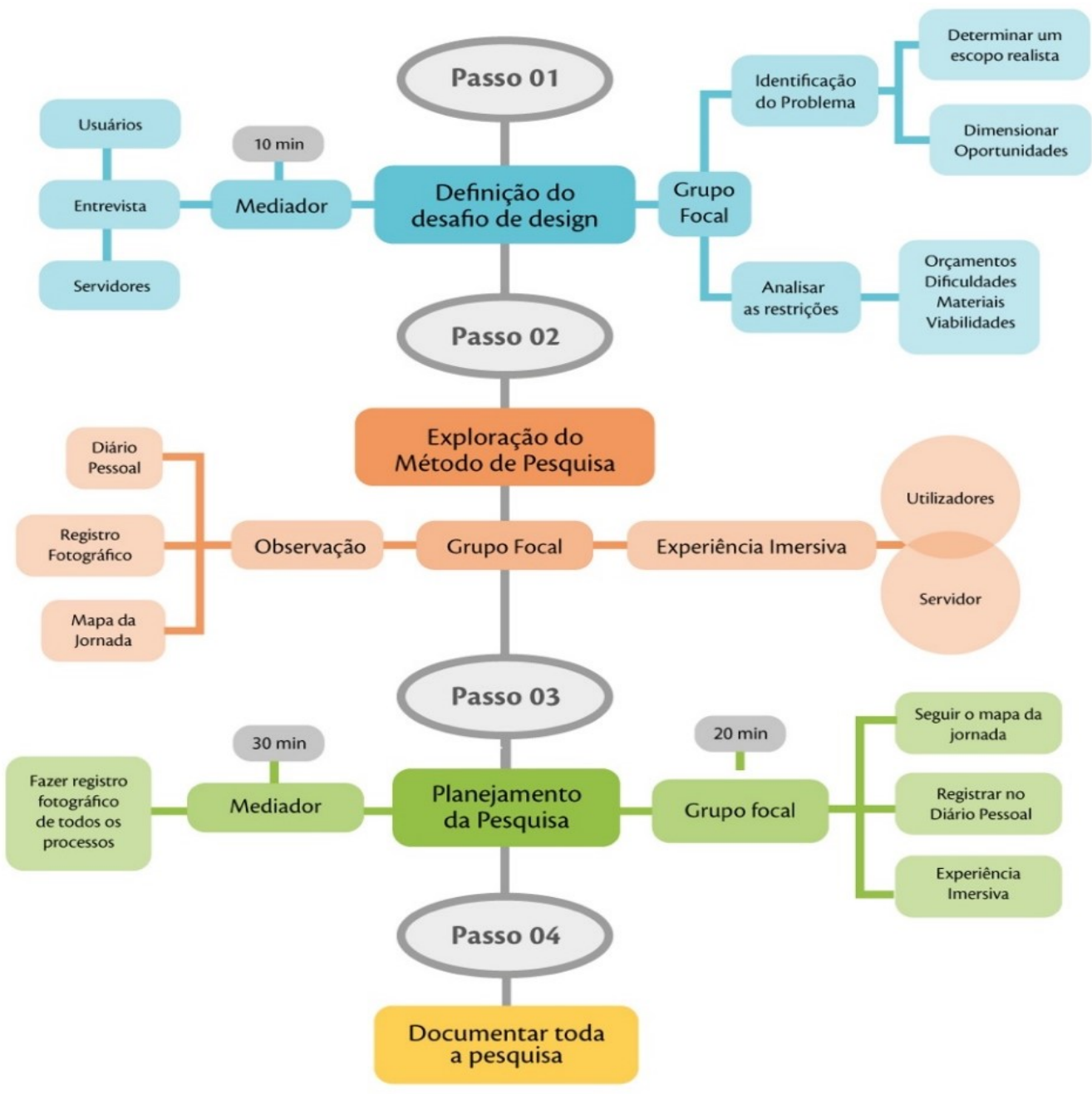

Fonte: Elaborado pelos Autores (2018). 
A fase de inspiração exigiu, portanto, conhecer um pouco dos usuários da biblioteca de modo que pudesse oferecer uma experiência imersiva no problema que aqui se tratava de identificar questões que ajudassem a trazer ideias que permitissem sinalizar melhor a biblioteca. A etapa seguinte será a ideação onde pretende-se desenvolver essas ideias.

\subsection{IDEAÇÃo}

O processo de ideação consiste na etapa de desenvolvimento de ideias. $\mathrm{Na}$ medida que são coletadas as características dos desafios na etapa de inspiração, os resultados são examinados e interpretados para sintetização de soluções. Esta etapa é dividida de acordo com o quadro 2:

Quadro 2 - Etapas do processo de Ideação

\begin{tabular}{|c|c|c|}
\hline Ação & Atividade & Objetivos \\
\hline Passo 1 & Compartilhamento de histórias & $\begin{array}{l}\text { - Relato de experiências } \\
\text { - Interpretação de comportamentos }\end{array}$ \\
\hline Passo 2 & Procura de temas & $\begin{array}{ll} & \text { Identificar padrões } \\
\text { - } & \text { Transformar temas em insights } \\
\text { - } & \text { Aplicar framework }\end{array}$ \\
\hline Passo 3 & Geração de Ideias & $\begin{array}{ll}\text { - } & \text { Brainstorming } \\
\text { - } & \text { Como poderíamos... } \\
\text { - } & \text { Votação das melhores ideias }\end{array}$ \\
\hline
\end{tabular}

Fonte: Elaborado pelos Autores (2018).

O primeiro passo para esta atividade consistiu no compartilhamento de histórias, em que os participantes relatam aos demais integrantes do grupo focal suas experiências vivenciadas no âmbito de bibliotecas. Para a IDEO (2017), o principal objetivo desta dinâmica é destacar áreas ricas de oportunidades. Com isso, o aprofundamento das diferentes perspectivas dos usuários auxiliou na compreensão mais detalhada do desafio da pesquisa. Sendo assim, munidos de cartolinas e post-its, os integrantes selecionaram os pontos mais relevantes para uma melhor interpretação de comportamentos e oportunidades.

O segundo passo teve por objetivo a identificação de temas e, para isso, foram divididas três etapas. A primeira foi a identificação de padrões, em que os participantes analisaram as notas observando onde havia incidência de repetições, buscando impulsionar novas ideias a partir dos temas identificados. 
A segunda etapa consistiu na transformação de temas em insigths, ou seja, na apresentação de boas ideias, tendo por princípio o uso do termo "e se" para instigar o desenvolvimento de boas propostas. $\mathrm{O}$ terceiro ponto foi realizado com a aplicação de frameworks, de modo que este foi utilizado as seguintes ferramentas (IDEO, 2017, p. 59):

- Dois por dois: Esta ferramenta ajuda a mapear aspectos de comportamentos e qualidades. Ela destaca as tensões entre categorias e pode apontar para as oportunidades de design dentro de cada quadrante.

- Mapa de relacionamento: Um mapa de relacionamento visualiza um conjunto de participantes usuários em seu serviço ou em uma organização. Também pode representar um fluxo de processos e conexões de um sistema maior.

No terceiro passo foi realizado a geração de ideias através do brainstorming, onde se utilizou o questionamento "como poderíamos" e, a partir dele, gerar soluções e ideias, procurando estabelecer as seguintes premissas: evitar julgamentos; incentivar ideias ambiciosas; construir a partir das ideias dos outros; manter-se focado no tema - não ter ideias desconexas ou longínquas do tema; Um diálogo por vez - cada integrante deve ouvir as ideias sem interrupções; ser visual - demonstre suas ideias por meio de desenhos ou esboços; e ir para a quantidade - tenha muitas ideias e em seguida realize um filtro.

Como forma de análise, ao final do processo de brainstorming, o grupo votou nas melhores ideias e soluções. Os resultados foram utilizados na construção das propostas de sinalização desenvolvidas pelo mediador. A etapa de Ideação pode ser melhor visualizada na figura 2 a seguir: 
Figura 2 - Passos de Ideação.

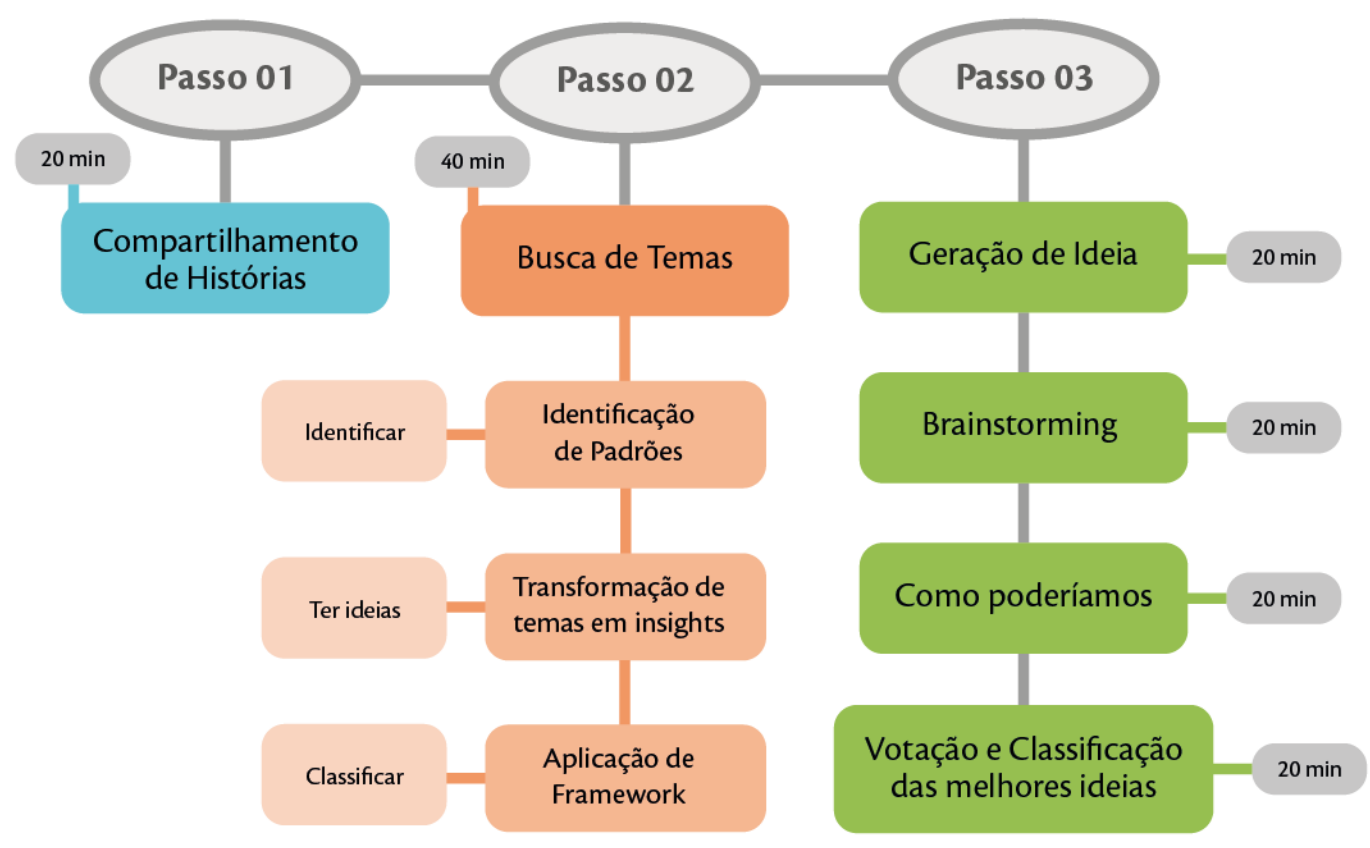

Fonte: Elaborado pelos Autores (2018).

Após termos obtido diversos insights com os usuários na ideação chegou a hora de experimentar as ideias sugeridas por eles na etapa de iteração para que o mediador pudesse depois elaborar protótipos de sinalizações da biblioteca.

\subsection{ITERAÇÃo}

Como o próprio nome já expressa, o processo de iteração compreende a experimentação de ideias buscando o feedback dos usuários, para que seja possível repetir e reanalisar detalhes não atendidos às expectativas do projeto. A partir da prototipagem e de sua simulação de implementação, os integrantes do grupo focal puderam visualizar melhor os resultados das propostas e iterar as questões insatisfatórias. Os passos desta etapa estão descritos no Quadro 3:

Quadro 3 - Passos de Iteração.

\begin{tabular}{|c|c|c|}
\hline Ação & Atividade & \multicolumn{1}{c|}{ Objetivos } \\
\hline Passo 1 & Prototipagem & $\begin{array}{l}\text { • Elaboração de ideias } \\
\text { • Visualizando propostas }\end{array}$ \\
\hline Passo 2 & Feedback & $\begin{array}{l}\text { - Feedback do grupo focal } \\
\text { - Sintetização dos comentários }\end{array}$ \\
\hline Passo 3 & IFinalização & - Analisar os resultados obtidos \\
\hline
\end{tabular}

Fonte: Elaborado pelos Autores (2018). 
A criação de protótipos trata da tangibilidade das ideias desenvolvidas nas etapas anteriores para experimentação ativa de sua implementação, possibilitando a visualização prévia dos resultados e, consequentemente, sua apropriada reavaliação. No passo dois, por sua vez, foi o momento em que os integrantes do grupo focal verificaram os resultados e pontuaram questões antes não observadas. Estas observações foram sintetizadas e os comentários estudados novamente com objetivo de aperfeiçoamento do projeto. Identificado todas as adequações necessárias, o terceiro passo consistiu na análise dos resultados.

Figura 3 - Passos Iteração.

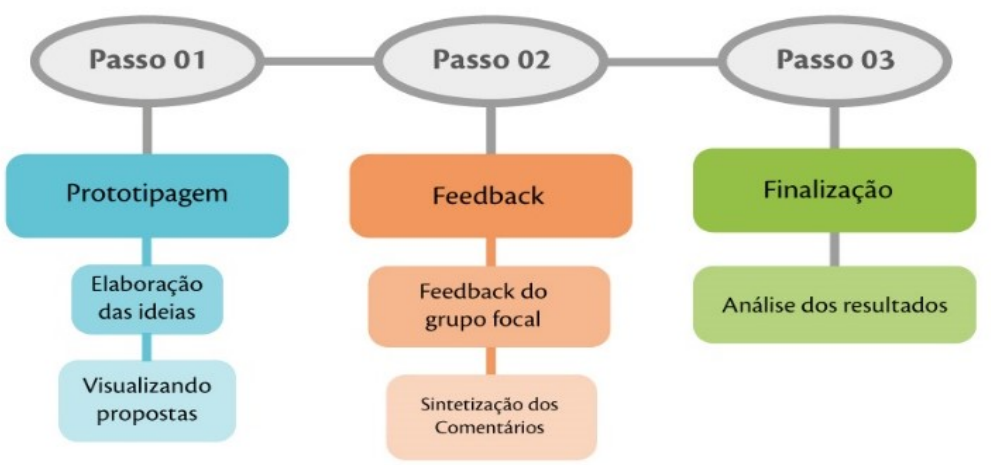

Fonte: Elaborado pelos Autores (2018).

Após a definição dos passos realizados na iteração, a subseção a seguir aborda as etapas e os resultados alcançados após as duas primeiras etapas do DT.

\subsection{DAS ETAPAS E DOS RESULTADOS}

O grupo focal ocorreu com a presença dos seis participantes convidados e o trabalho iniciou com um breve esclarecimento das regras para realização das atividades. Desse modo, por desconhecimento dos integrantes, viu-se necessário apresentar o conceito de design thinking e as suas principais características, tais como: é uma abordagem centrada no usuário; é prática (pensar fazendo); é visual; trata de pensamentos divergentes e convergentes; é colaborativa e visa resultados econômicos. Além disso, no que se refere as relações cooperativas entre ideias e pensamentos, foram apresentadas as 
regras para aplicação da dinâmica, por exemplo: evitar julgamentos; incentivar ideias ambiciosas; construir a partir das ideias dos outros; manter- se focado no tema; um diálogo por vez; ser visual; gerar muitas ideias para depois filtrálas.

$\mathrm{Na}$ oportunidade, foram expostas as principais observações coletadas a partir das dez entrevistas realizadas pelo mediador, tendo como pontos positivos os relatos de que 1) o espaço da atual biblioteca melhorou bastante em comparação ao ambiente anteriormente improvisado; 2) os servidores possuem um bom atendimento; 3) a sinalização é regular; 4) a iluminação e temperaturas são adequadas. Contudo, contrapondo a estas questões, a biblioteca possui diversas deficiências de 1) localização, tanto de seus espaços, quanto do próprio acervo; 2) acesso físico inapropriado para pessoas com deficiência; 3 ) há problemas ergonômicos nas mesas, cadeiras e estantes; 4) as mesas estão localizadas abaixo de aparelhos de arcondicionado, com temperaturas que acabam incomodando os alunos; 5) não há privacidade para estudo; 6) os cadeirantes possuem diversos limites de locomoção no acervo; 7) o piso é muito derrapante; 8) não foram percebidos mídias de divulgação de eventos da biblioteca.

Após a conclusão destas explanações, os participantes foram convidados a se deslocarem para a entrada do campus munidos de 1) pranchetas, cada qual contendo dez folhas em branco do tamanho A4 para serem utilizadas como diário pessoal; 2) um mapa de jornada da biblioteca com os principais setores do local; 3) o Termo de Consentimento Livre e Esclarecido, onde os integrantes puderam formalizar seus aceites de participação; 4) canetas.

A partir de então, equipado com estas ferramentas, o grupo deslocou-se desde a entrada do campus, percorrendo todo o pátio principal, até explorar toda a área interna da própria biblioteca, percebendo, sentindo e experimentando as adversidades ergonômicas e de sinalização. A medida que as dificuldades surgiam, o grupo fazia as suas anotações no diário e compartilhavam ideias. As imagens da Figura 4 a seguir mostram alguns percursos ao longo do processo. 
Figura 4: Caminho de acesso à Biblioteca Central da UFCA

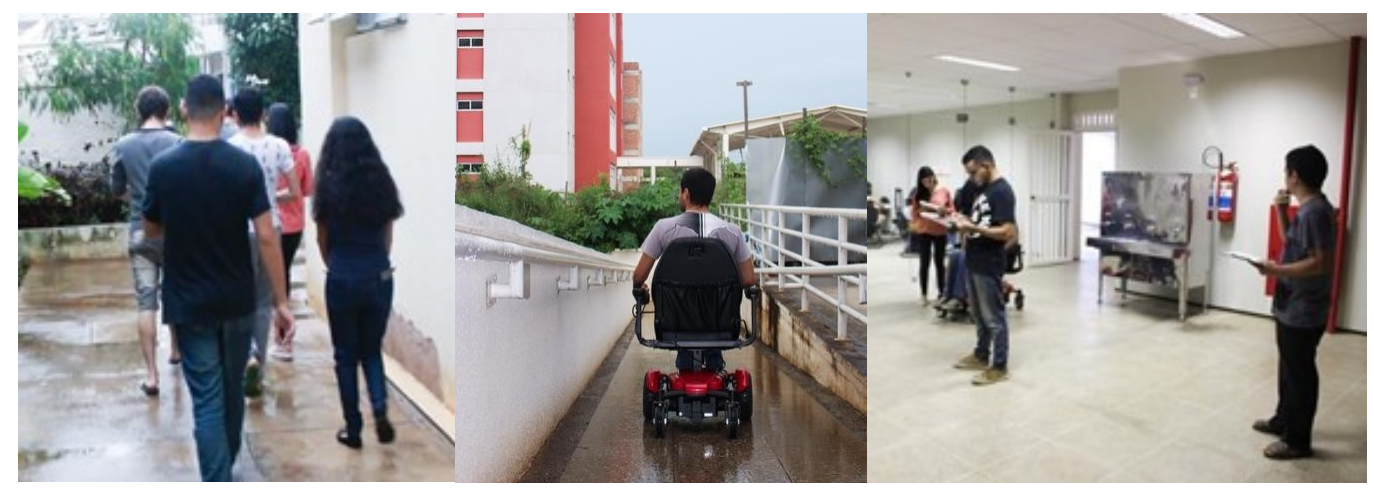

Fonte: Elaborada pelos Autores (2018).

Concluída esta etapa de inspiração, ao retornar para a sala G008, o grupo iniciou a etapa de Ideação. Primeiramente foram apresentados alguns relatos pessoais de experiências vivenciadas em bibliotecas. Histórias que pudessem contribuir com o amadurecimento de ideias e sensibilizar os participantes a respeito de fatos comuns. Dentre os assuntos destacaram-se problemas físicos, ergonômicos e informacionais, tais como a altura dos livros em prateleiras e suas localizações, o esforço para abrir a porta principal de vidro da biblioteca e a compreensão da distribuição dos códigos dos livros.

Logo em seguida o grupo dividiu em sete folhas de tamanho A3 cada área analisada: pátio, entrada (da biblioteca), sala de estudos I, balcão de atendimento, ala de estudos e acervo. Com os post-its e canetas hidrocor, os participantes escreveram todos os problemas e dificuldades encontradas em cada um destes espaços. O objetivo foi apresentar todos os problemas levantados no processo de inspiração para posteriormente identificar os padrões, obter ideias e classificar através da aplicação dos frameworks. O passo seguinte, portanto, fomentou a classificação dos principais aspectos de sinalização identificados pelo grupo focal utilizando a ferramenta de framework dois por dois. Para esta ferramenta foram analisados 0 alto engajamento e 0 baixo engajamento, considerando o nível de influência das questões identificadas no processo de inspiração para o melhoramento da biblioteca. Desse modo, de acordo com o engajamento, ou seja, a relevância do problema para a estrutura e a sinalização da biblioteca, o post-it foi locado mais próximo 
ao polo superior, o mesmo princípio foi utilizado para a inadequação ou irrelevância, sendo este posicionado no polo inferior ao quadrante.

Para os polos esquerdo e direito foram definidos os aspectos de condução emocional e condução funcional, respectivamente. A condução funcional atribui às suas classificações as influências emocionais das ideias observadas pelo grupo focal. Os elementos que causam frustação nos utilizadores, como por exemplo a inadequação dos corredores do acervo para o retorno e rotatividade de um cadeirante, são classificados como elemento de alta influência emocional. Por outro lado, quando os aspectos observados são de alto impacto funcional, ou seja, elementos avaliados pelas suas funções, são distribuídos para o polo direito. Ao final, os painéis obtiveram alguns dos seguintes resultados:

Figura 5 - À esquerda, painel de problematização; à direita, framework dois por dois

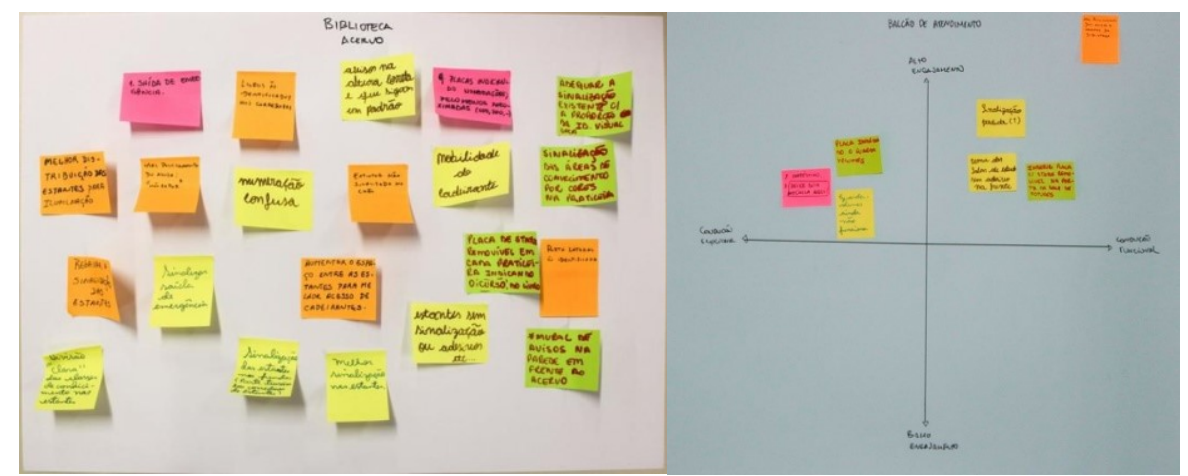

Fonte: Elaborada pelos autores (2018).

Por meio do brainstorming e pela estrutura condutora de proposta "como poderíamos", o grupo focal construiu ideias para solucionar os diferentes problemas. Paralelo ao método, foi utilizado o framework "mapa de relacionamento" para conduzir os raciocínios. Dessa maneira, para cada área analisada foram delimitadas ligações entre os diversos conceitos, buscando relacionar problemas, soluções e criação das peças gráficas de sinalização. A figura 6 ilustra os resultados da dinâmica, onde pode-se perceber o fluxo de pensamento e a ligação entre as ideias por meio do Mapa de Relacionamentos. 
Figura 6 - Mapas de Relacionamentos

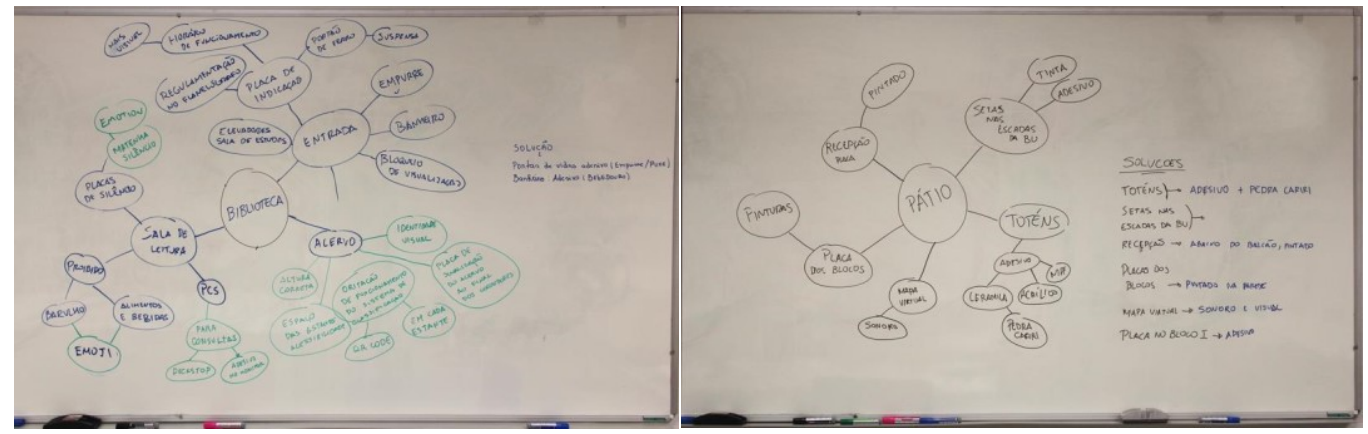

Fonte: Elaborada pelos autores (2018).

Deste modo, para sintetizar elaborou-se o quadro 04 para descrever as ferramentas utilizadas bem como os resultados obtidos.

\section{Quadro 4 - Resultados das ferramentas de Design Thinking empregadas na pesquisa.}

\begin{tabular}{|c|c|c|c|}
\hline Etapa & $\begin{array}{c}\text { Ferramenta de } \\
\text { DT }\end{array}$ & Objetivo & Resultados \\
\hline \multirow{3}{*}{ 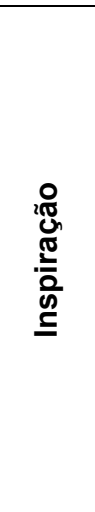 } & Diário Pessoal & $\begin{array}{l}\text { Documentar as observações } \\
\text { ao longo de um percurso }\end{array}$ & $\begin{array}{l}\text { Possibilitou notificar as informações } \\
\text { observadas no espaço da biblioteca para } \\
\text { facilitar seu resgate posterior. }\end{array}$ \\
\hline & $\begin{array}{l}\text { Registro } \\
\text { Fotográfico }\end{array}$ & $\begin{array}{l}\text { Registrar os espaços, } \\
\text { equipamentos, sinalizações } \\
\text { e a dinâmica do grupo }\end{array}$ & $\begin{array}{l}\text { Facilitou a visualização e memorização } \\
\text { das etapas do processo, auxiliando no } \\
\text { resgate visual das informações e } \\
\text { reforçando a representação fotográfica dos } \\
\text { problemas identificados na biblioteca. }\end{array}$ \\
\hline & $\begin{array}{l}\text { Mapa de } \\
\text { Jornada }\end{array}$ & $\begin{array}{l}\text { Orientar quanto ao espaço a } \\
\text { ser percorrido e facilitar } \\
\text { anotações pontuais para } \\
\text { cada setor. }\end{array}$ & $\begin{array}{l}\text { Situou os participantes quanto as divisões } \\
\text { do espaço da biblioteca, possibilitando } \\
\text { anotações específicas para cada divisão } \\
\text { do ambiente, garantindo melhor } \\
\text { visualização e análise de implementação } \\
\text { do sistema de sinalização. }\end{array}$ \\
\hline \multirow[t]{2}{*}{$\begin{array}{l}\text { ㅇ్ల } \\
\underset{\mathbb{Z}}{\mathbb{0}} \\
\stackrel{0}{0}\end{array}$} & Dois por Dois & $\begin{array}{l}\text { Classificar a relação de } \\
\text { antítese entre aspectos a } \\
\text { serem analisados }\end{array}$ & $\begin{array}{l}\text { Avaliou-se um determinado assunto sobre } \\
\text { a perspectiva de antítese, em que o } \\
\text { posicionamento do conteúdo determinou o } \\
\text { seu valor dentro do contexto analítico. } \\
\text { Assim, foi capaz de organizar os pontos } \\
\text { observados dentro do seu nível de } \\
\text { importância e engajamento. }\end{array}$ \\
\hline & $\begin{array}{l}\text { Mapa de } \\
\text { Relacionamento }\end{array}$ & $\begin{array}{l}\text { Rede de conexões visuais } \\
\text { que possa contribuir com o } \\
\text { fluxo de ideias }\end{array}$ & $\begin{array}{l}\text { Flexibilizou a visualização e gerenciamento } \\
\text { das ideias, interligando pontos específicos } \\
\text { dentro de uma rede de conexões, } \\
\text { promovendo ideias inovadoras às } \\
\text { necessidades das bibliotecas. }\end{array}$ \\
\hline
\end{tabular}

Fonte: Elaborado pelos autores (2019).

Com base nas informações coletas a partir das ideias geradas pelo grupo focal, foram desenvolvidas as principais peças gráficas observando e respeitando a normatização da ABNT 9050 e considerando ainda as orientações do manual de sinalização da UFCA. Este último, traz especificações importantes sobre as peças que compõe o sistema de sinalização e suas diversas características técnicas, sendo, portanto, referência para a construção e 
instalação dos materiais da sinalização da universidade. As Figuras 7 e 8 a seguir apresentam apenas uma simulação do resultado final da proposta de sinalização, ou seja, não correspondem a resultados de implementações reais do projeto final, já que os recursos foram insuficientes. Portanto, o estudo aqui abordado não chegou a ser materializado por questões econômicas, embora os resultados tenham sido conceituados como satisfatórios pelo grupo focal.

Figura 7 - Portas de entrada da biblioteca atual e proposta.

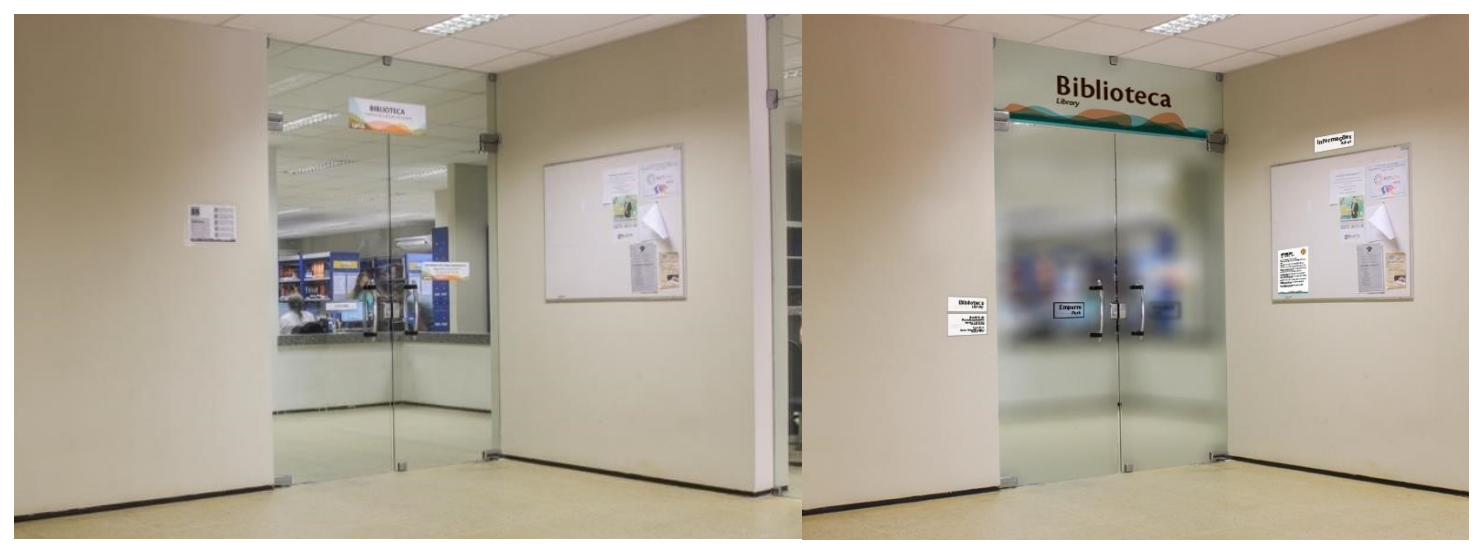

Fonte: Elaborada pelos Autores (2019).

Figura 8 - Simulação de sinalização das placas informativas das estantes

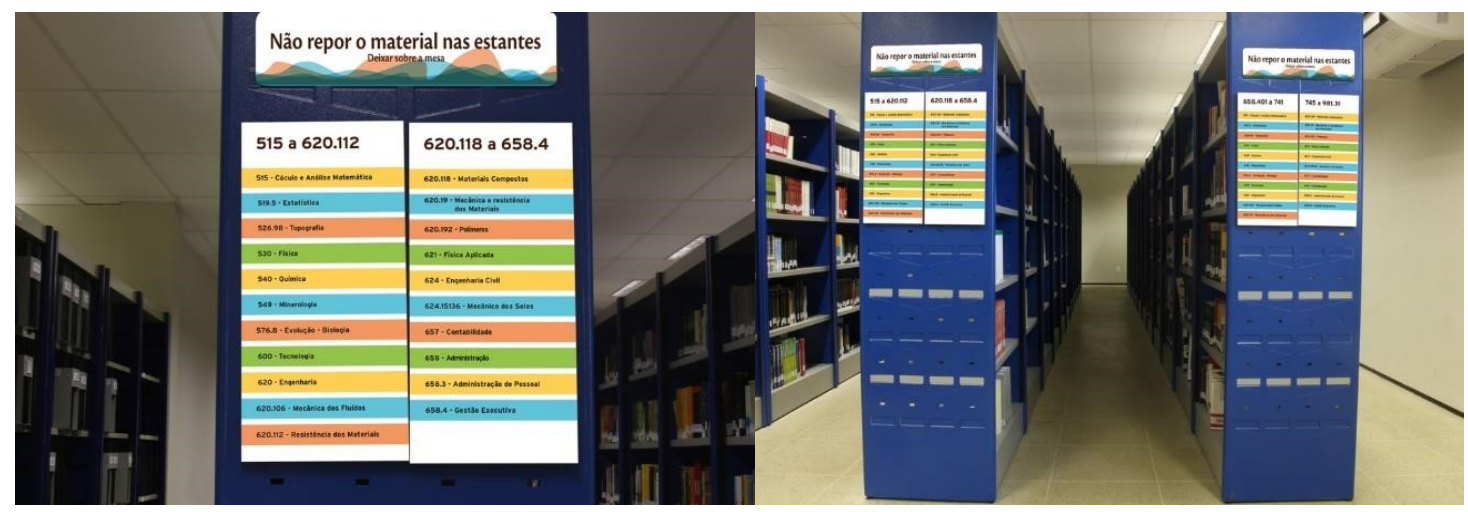

Fonte: Elaborada pelos Autores (2019).

Diante destas propostas de peças gráficas que foram produzidas com intuito de melhorar a sinalização da biblioteca a próxima seção traz as considerações finais da pesquisa.

\section{CONSIDERAÇÕES FINAIS}

A princípio, as investigações realizadas nesta pesquisa buscaram 
encontrar ferramentas eficientes para a identificação das necessidades dos utilizadores do espaço da biblioteca, principalmente por entender a representação humana como elemento central de suas atividades. Neste sentido, entre diferentes abordagens, optou-se pelo Design Thinking por compreender que esta metodologia é pautada nos princípios de inovação e por executar seus métodos por meio de ações coletivas e interdisciplinares, possibilitando sujeitos ativos no processo. Antes, porém, a coleta de dados por intermédio das entrevistas demonstrou resultados satisfatórios, pois contribuíram com informações fundamentais relativas a infraestrutura, localização, serviços e produtos e de acessibilidade. Cuidados que envolvem seriamente a qualidade da biblioteca e de toda a universidade.

Entre as oportunidades identificadas neste estudo vale destacar o valioso envolvimento dos próprios usuários com o planejamento e as estratégias da biblioteca da UFCA, comprometidos em idealizar soluções criativas por intermédio de observações próprias enquanto principais utilizadores do espaço. Os sentimentos de partilha, empatia e colaboração também permitiram aos envolvidos uma postura protagonista e entusiasmada na busca de soluções. Portanto, essa interdisciplinaridade dos integrantes, que demonstrou diferentes perspectivas, ampliou os benefícios recorrentes da coleta de dados da etapa de inspiração, das ideias inovadoras da ideação e dos testes reavaliadores da iteração.

Por fim, o que se pode desejar é que as experiências contidas neste estudo possam estimular ainda mais: a prática dos métodos do Design Thinking para inovações criativas; com a otimização de sistemas de sinalização das bibliotecas; com a integralização e cooperação dos usuários com as diferentes atividades destes ambientes; e, por fim, para maior aproximação entre os profissionais que se dedicam a biblioteconomia e ao design.

\section{REFERÊNCIAS}

BERNAL-RAMÍREZ, Diana Marcela; ZANINELLI, Thais Batista. O uso do design thinking como ferramenta no processo de inovação em bibliotecas.

Encontros Bibli: revista eletrônica de biblioteconomia e ciência da informação, 
v. 22, n. 49, p. 59-74, maio, 2017. Disponível em: https://periodicos.ufsc.br/ index.php/eb/article/view/1518-2924.2017v22n49p59/34048. Acesso em: 06 ago. 2019.

BROWN, Tim. Design thinking. Harvard Business Review, v. 86, n. 6, p. 8592, jun. 2008.

BURGUILLOS, Ferran. Design Thinking for Libraries: piensa el futuro de la biblioteca como lo haría un diseñador. Anuário ThinkEPI, v. 10, p. 109-112, 2016. Disponível em: https://recyt.fecyt.es/index.php/ThinkEPI/article/view/think epi.2016.19/30530. Acesso em: 05 jul. 2019.

GIL, Antônio Carlos. Métodos e técnicas de pesquisa social. 6. ed. São Paulo: Atlas, 2012.

IDEO. (2017). Design Thinking For Library. (Fundação Bill\&Melinda Gates) Acesso em 2017. Disponível em:http://designthinkingforlibrary.com. Acesso em: 10 abr. 2018.

JOHN, Gemma. Designing libraries in 21st century: lessons for the UK. London: British Council, 2016.

JULIANI, Jordan; CAVAGLIERI, Marcelo; MACHADO, Raquel. Design Thinking como ferramenta para a geração de inovação: um estudo de caso da Biblioteca Universitária da UDESC. InCID: R. Ci, Inf. e Doc. Ribeirão Preto, v. 6, n. 2, p. 66-83, set., 2015.

MACEDO, Paula A.; SANTOS, Ana M. S. Design Thinking para bibliotecas. In: PRADO, Jorge. (org.) Ideias emergentes em Biblioteconomia. São Paulo: FEBAB, 2016.

MELO, Adriana; ABELHEIRA, Ricardo. Design Thinking \& Thinking design: metodologia, ferramentas e uma reflexão sobre o tema. São Paulo: Novatec, 2015.

PINHEIRO, Tennyson. Design Thinking Brasil: empatia, colaboração e experimentação para pessoas, negócios e sociedade. Rio de Janeiro: Elsevier, 2011.

\title{
DESIGN THINKING ON THE CREATION OF A UFCA ACADEMIC LIBRARY SIGNALING PROPOSAL: RESEARCH REPORT
}

\begin{abstract}
Introduction: Faced with the changes that have taken place in recent years in the academic library environment, the management of this space faces a new type of user already used to information technology that has created new yearnings. The signage
\end{abstract}


should then be thought for this type of user as well as extend also to the issue of accessibility so it is important to review the services and products offered by the library within this approach. Objective: It presents a research report on the design of signaling solutions using Design Thinking tools with the engagement of users from the Central Library of the Universidade Federal do Cariri (UFCA). Methodology: Qualitative in nature the study comprised the use of a focus group where ten users of the Academic Library of UFCA were interviewed. Practical in nature and with exploratory objectives, its approach was in the action research format, aiming to promote the cooperation of users of the Juazeiro do Norte Campus library in the design of environmental signaling solutions. Results: Collaborative engagement among participants was perceived, involving them in a protagonist and enthusiastic way to the challenges of identifying problems and proposing solutions for the library. The use of Design Thinking steps and tools, although recorded in a linear manner, sought to fit the process satisfactorily according to the focus group's own report. Conclusions: The collaboration between the Design and Information Science disciplines represents an opportunity to bring Design Practice closer together in order to optimize library signaling systems, although it has been shown that the approached methods are capable of achieving even broader solutions. Above all, the main highlight to consider is the insertion of users as a fundamental part in the planning and strategies of the information science field.

Descritors: Design Thinking. Academic Library. Sineage. Tools.

\title{
DESIGN THINKING EN EL DISEÑO DE UNA PROPUESTA DE SEÑALIZACIÓN DE LA BIBLIOTECA UNIVERSITARIA DE LA UFCA: INFORME DE INVESTIGACIÓN
}

\begin{abstract}
RESUMEN
Introducción: Ante los cambios que han tenido lugar en los últimos años en el entorno de la biblioteca universitaria, la gestión de este espacio se enfrenta a un nuevo tipo de usuario ya acostumbrado a la tecnología de la información que ha creado nuevos deseos. La señalización debería pensarse para este tipo de usuario, así como extenderse también al tema de la accesibilidad, por lo que es importante revisar los servicios y productos ofrecidos por la biblioteca dentro de este enfoque. Objetivo: Presenta un informe de investigación sobre el diseño de soluciones de señalización utilizando herramientas Design Thinking con el compromiso de los usuarios de la Biblioteca Central de la Universidade Federal de Cariri (UFCA). Metodología: De naturaleza cualitativa, el estudio comprendió el uso de un grupo focal donde se entrevistó a diez usuarios de la Biblioteca de la Universidad de UFCA. De naturaleza práctica y con objetivos exploratorios, su enfoque fue en el formato de investigación de acción, con el objetivo de promover la cooperación de los usuarios de la biblioteca del Campus Juazeiro do Norte en el diseño de soluciones de señalización ambiental. Resultados: Se percibió el compromiso de colaboración entre los participantes, involucrándolos de manera protagonista y entusiasta ante los desafíos de identificar problemas y proponer soluciones para la biblioteca. El uso de pasos y herramientas de Design Thinking, aunque registrado de manera lineal, buscó ajustar el proceso satisfactoriamente de acuerdo con el propio informe del grupo focal. Conclusiones: La colaboración entre las disciplinas de Diseño y la Ciencia de la Información representa una oportunidad para acercar la práctica de diseño a fin de optimizar los sistemas de
\end{abstract}


señalización de la biblioteca, aunque se ha demostrado que los métodos abordados son capaces de lograr soluciones aún más amplias. Sobre todo, lo más destacado a considerar es la inserción de los usuarios como parte fundamental en la planificación y las estrategias del campo de la Ciencia de la Información.

Descriptores: Design Thinking. Bibliotecas Universitárias. Señalización. Herramientas.

Recebido em: 19.08.2019

Aceito em: 09.09.2019 